Original Research

\title{
Effect of Recycled Rubber Particles on the Deicing Salt-Scaling Durability of Concrete
}

Layachi Guelmine ${ }^{1,}{ }^{*}$, Hadda Hadjab ${ }^{2}$

1. Civil Engineering Department, B.B.A University, BP34030, Bordj Bou-Arréridj, Algeria; E-Mail: layachi.guelmine@univ-bba.dz

2. Civil Engineering Faculty, USTHB, FGC BP32, Bab Ezzouar, Alger, Algeria; E-Mail: hhadjab@usthb.dz

* Correspondence: Layachi Guelmine; E-Mail: layachi.guelmine@univ-bba.dz

Academic Editor: Jorge de Brito

Special Issue: Wastes, Residues and Byproducts for the Production of Construction Materials

Recent Progress in Materials

2021, volume 3, issue 3

doi:10.21926/rpm.2103033
Received: March 27, 2021

Accepted: July 02, 2021

Published: August 09, 2021

\begin{abstract}
The present study investigated the effect of reused rubber particles (RRP) on the deicer salt durability of ordinary concrete. Four mixtures were designed, a control concrete (CC) and three other rubber concretes obtained by partial substitution of natural dune sand aggregate with reused rubber particles with $0 \%, 3 \%, 6 \%$, and $9 \% \mathrm{w} / \mathrm{w}$. All studied concretes were subjected to the combined effect of freeze/thaw (56 and 120) cycles with the deicer salt solution of $3 \% \mathrm{NaCl}$. The results indicated that RRP improved the deicer-salt scaling resistance of rubber concrete strongly compared with the control. The observed innovative property of RRP could be applied to cement-based materials to improve their deicer salt durability. Further, this environmentally friendly practice could reduce the stock of waste tires and offer a renewable source of construction aggregates.
\end{abstract}

\section{Keywords}

Reused rubber waste; air content; surface scaling; deicer salt scaling durability; wateruptake

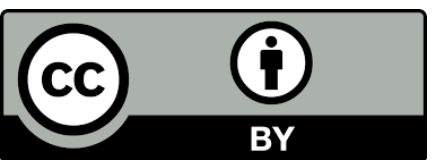

(C)2021 by the author. This is an open access article distributed under the conditions of the Creative Commons by Attribution License, which permits unrestricted use, distribution, and reproduction in any medium or format, provided the original work is correctly cited. 


\section{Introduction}

The use of industrial vehicles produces a huge quantity of waste rubber tires. The manufacturers indicate the annual world production of waste tires was 1.4 billion units per year [1]. The bad management of waste tires, such as incineration and landfills, threatens the environment, contaminating the air, soil, and water sources through toxic compounds [2]. The latest global initiatives to protect the environment recommend the use of cleaner methods for waste disposal [1, 2]. Certainly, reusing the waste rubber tires for applications, such as construction aggregates, could protect the environment and reduce their accumulation in landfills.

Rubber waste tires decompose over hundreds of years. Thus, they can be used to improve the deicing salt durability of concrete. Notably, the deicing salt damage to concrete is caused by the combined effect of freeze-thaw cycles with deicing salts attack. Surface scaling is the primary damage of deicing salt on concrete [3]. The use of deicing salts on concrete structures enables the dissolution of the accumulated ice to facilitate vehicles and people on roadways during winter.

Various studies have investigated the substitution of natural aggregates with reused rubber particles of waste tires RRP in concrete or mortar mixtures at different rates $[3,4]$. The results indicated RRP induced significant reductions in the elastic modulus and compressive and tensile strength of rubber concrete [3-5]. Other studies revealed that RRP improved the rubber concrete properties, such as toughness, deformation capacity, energy absorption, ductility, and strain capacity compared with the control concrete without RRP [6, 7]. Earlier research has also shown that RRP has a strong potential to introduce air into concrete mixtures, including rubber aggregates [8].

Further, reused rubber aggregates could significantly improve the concrete durability to freezethaw cycles $[2,8,9]$. However, the durability of rubber concrete subjected to the combined effect of freeze-thaw cycles with deicing salts attack is rarely reported.

This study investigated the effect of the RRP on the durability of ordinary concrete subjected to freeze-thaw with deicing salts solution. Four types of concrete were prepared: a control concrete (CR) and three other rubber concretes obtained by the inclusion of reused rubber particles by partial substitution with dune sand at a rate of $3 \%, 6 \%$, and $9 \%$, by mass. The durability of concrete mixtures was evaluated by visual observation, saturation rate (water-uptake), and scaling surface after the different exposures.

\section{Experimental Investigation}

\subsection{Materials}

The concrete components were cement, natural aggregate, tap water, and reused rubber particles (RRP). Ordinary Portland Cement CEM II/A 42.5, with a bulk density of $3080 \mathrm{~kg} / \mathrm{m}^{3}$, was used in the experiments. The natural dune sand (NDS) of a size grading and apparent density of $0.08-2.5 \mathrm{~mm}$ and $1530 \mathrm{~kg} / \mathrm{m}^{3}$, respectively, was used as fine aggregate, and natural gravel of maximum size of $16 \mathrm{~mm}$ was used as coarse aggregate. The reused rubber particles (RRP) were obtained by shredding rubber tire waste. Their apparent density was $450 \mathrm{~kg} / \mathrm{m}^{3}$ (Figure 1). The 
RRP was included in the concrete mixtures $(0.1-2.5 \mathrm{~mm})$ by partial substitution with sand aggregate. Figure 2 shows the sieve analysis results of the used aggregates.

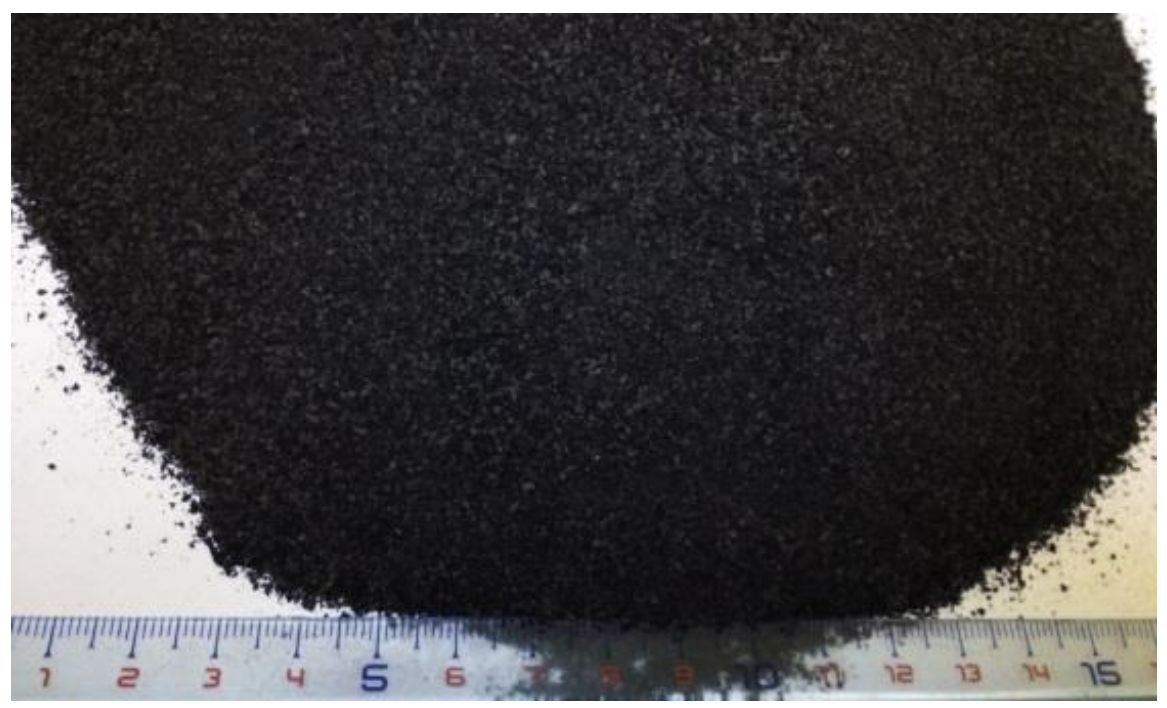

Figure 1 Reused Rubber Particles RRP.

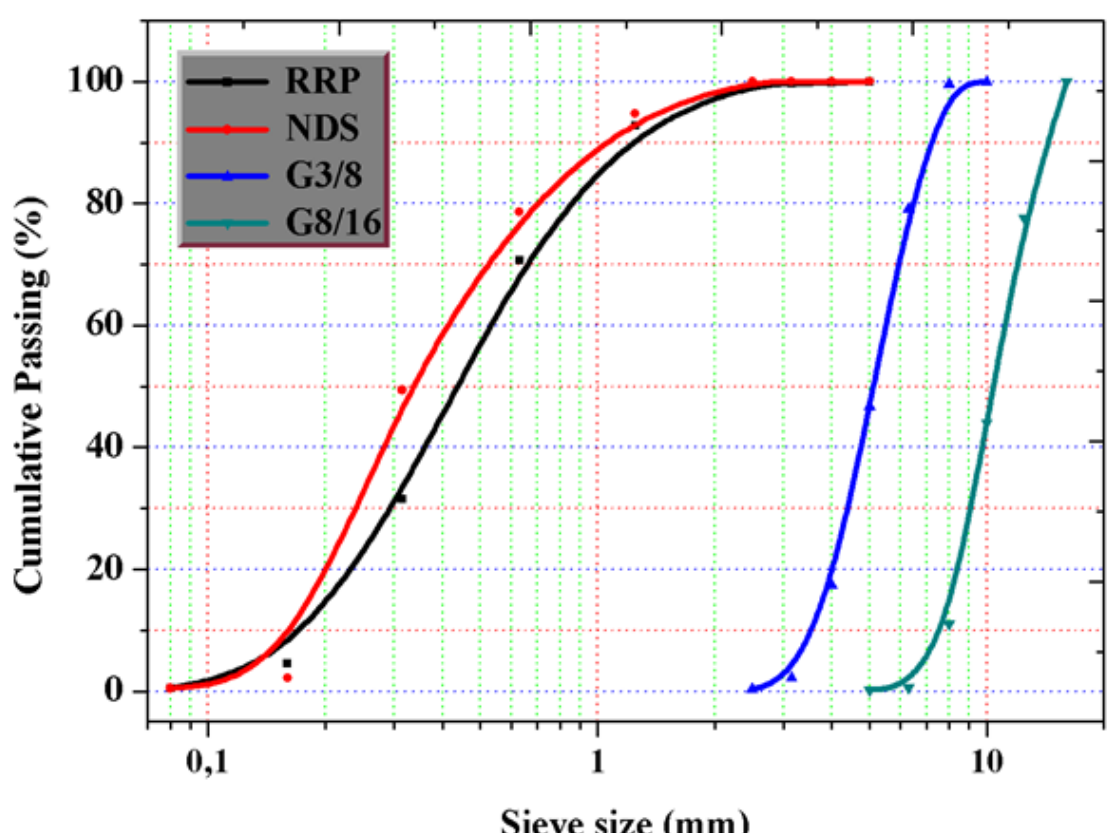

Figure 2 Grading cures of the NDS, the coarse aggregates (G3/8, G8/16), and the RRP.

\subsection{Mix Proportions}

In order to evaluate the effect of the RRP on the durability to deicer salt of concrete, four concrete were produced: The control concrete (CC) was ordinary concrete designed according to the Dreux-Gorisse method [10], and three other rubber concretes were obtained by partial substitution of dune sand with an equal mass of RRP, at different rates of $3 \%, 6 \%$, and $9 \%$. All water-cement ratios of concrete specimens were maintained as 0.53 for a reliable comparison. Table 1 represents the composition of all mixtures. 
Table 1 Proportions of concrete mixtures.

\begin{tabular}{ccccc}
\hline \multirow{2}{*}{ Component } & \multicolumn{4}{c}{ Concrete mixtures (kg) } \\
& CC & CRRP 3\% & CRRP 6\% & CRRP 9\% \\
\hline Natural Dune Sand & 620 & 602 & 583 & 564 \\
Coarse aggregate 3/8 & 175 & 175 & 175 & 175 \\
Coarse aggregate 8/16 & 985 & 985 & 985 & 985 \\
Cement & 400 & 400 & 400 & 400 \\
Water & 212 & 212 & 212 & 212 \\
RRP & 0 & 18.60 & 37.20 & 55.80 \\
\hline
\end{tabular}

All concretes were mixed and prepared as per the European Standard NF EN 12390-2 [10]. At first, the concrete specimens were cast in $100 \times 100 \times 100 \mathrm{~mm}^{3}$ molds. After $24 \mathrm{~h} \pm 1 \mathrm{~h}$, the specimens were unmolded and placed in saturated lime water for 28 days $\left(T=20 \pm 2{ }^{\circ} \mathrm{C}, \mathrm{HR}=\right.$ $100 \%)$ and then in a laboratory environment $\left(T=20 \pm 2{ }^{\circ} \mathrm{C}\right.$ and $\left.H R=50 \pm 5 \%\right)$ until tested. The letters, $C, R, R$, and $\mathrm{P}$, represent Concrete, Reused, Rubber, Particles, respectively. For example, CRRP $3 \%$ indicates the concrete with $3 \%$ recycled rubber particles of waste tires by substituting with natural dune sand.

\subsection{Deicer Salt-Scaling Test}

This test estimated the effect of reused rubber particles on the deicing salt-scaling durability of the studied concretes subject to the combined effect of freeze-thaw cycles in the presence of a deicing salt solution, i.e., $3 \% \mathrm{NaCl}$. The standard cycle included two stages. Initially, the specimens were subjected to a freeze sequence of $18 \pm 1 \mathrm{~h}$ in a refrigerator environment with a fall speed temperature of $-2.5 \pm 0.5^{\circ} \mathrm{C}$. The cycle ended with a thawing stage in a saltwater $(3 \% \mathrm{NaCl})$ tank for $6 \pm 1 \mathrm{~h}\left(20 \pm 2{ }^{\circ} \mathrm{C}\right)$. The deicing salt test was realized by a similar process of ASTM C672 standard [11] on 40 days aged prismatic specimens $\left(10 \times 10 \times 10 \mathrm{~cm}^{3}\right)$. The refrigerator had a temperature range of 0 to $-30{ }^{\circ} \mathrm{C}$ with a fall speed of $-2.5 \pm 0.5^{\circ} \mathrm{C} / \mathrm{min}$. Studies have reported that deicing salt, such as sodium chloride, produces more severe concrete deterioration than only freeze-thaw attacked concrete [12-14]. The pre-saturation and thaw phases of the specimens were performed in a $3 \%$ $\mathrm{NaCl}$ salt solution. The $3 \%$ concentration was selected after a thorough literature review of the maximal concentration (pessimum) of $\mathrm{NaCl}$ producing the maximal deicing salt scaling $[15,16]$. The surface scaling of concrete specimens was analyzed after 56 cycles and 120 cycles. The deicer salt durability of the studied concretes was measured by their saturated rate and deicing saltscaling resistance.

The scaling surface Qs $\left(\mathrm{g} / \mathrm{m}^{2}\right)$ was used to evaluate the specimens damaged by the combined effect of freeze/thaw cycles with deicing salt according to the standard ASTM C672 [11] as follows:

$$
Q s=m / A
$$


where $m$ is the scaling mass in grams after each exposure threshold and $A$ is the total area specimen in $\mathrm{m}^{2}$.

\subsection{Test Methods}

In order to evaluate the deicing salt scaling durability of the studied concretes, entrapped-air test, deicing salt-scaling, and saturation rate were determined. The specific properties of various mixtures were evaluated on three prismatic specimens of $10 \times 10 \times 10 \mathrm{~cm}^{3}$. The properties measured on the fresh CRRP included air content. These tests were performed following the ASTMC231 Standards [17]. The saturation rate of the studied concrete exposed to the combined effects of freeze-thaw cycles with deicer salt was evaluated as follows:

$$
S_{r}(\%)=\left(\frac{m_{\text {sat }-m_{d r y}}}{m_{d r y}}\right) \times 100
$$

A uniaxial compression test as per the European Standard was used to measure the compressive strength. The compression test was performed on cubic specimens of $10 \times 10 \times 10$ $\mathrm{cm}^{3}$ at the end of the deicing salts test. Three specimens were crushed for each composite, and each was exposed to deicing salt, using a hydraulic press with a maximum force of $1000 \mathrm{kN}$.

\section{Results and Discussion}

\subsection{Air Content}

Figure 3 illustrates the air content of the studied concretes as a function of the RRP content. The observed results showed an increase in air content with an increase in rubber sand RRP. For the RRP rate up to $9 \%$, the air content varied from $1.5 \%$ to $5.3 \%$. Further, the supplementary air content of CRRP $9 \%$ was $3.8 \%$ compared with the control concrete. This trend could be due to the rubber particles' topography behaving like a magnet to attract air bubbles on their rough surface. Many researchers have observed a similar trend for rubber concrete $[18,19]$. The revealed innovative property of RRP could be applied for cement-based materials to enhance their deicing salt durability.

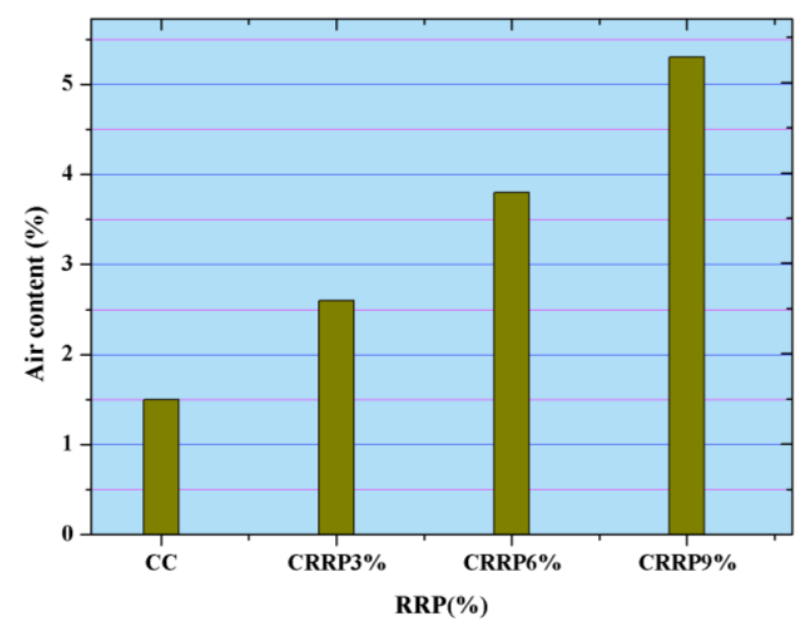

Figure 3 Effect of RRP on the air content of the studied concretes. 


\subsection{Deicing Salt-Scaling Durability}

The study also evaluated the results of the deicing salt test of the concretes included RRP. The deicing salt damage of the studied concrete was determined by the visual observation, saturation rate, and surface scaling resistance. Table 2 summarizes the corresponding average results obtained.

Table 2 Deicing salt test results for the studied concretes.

\begin{tabular}{lllll}
\hline \multirow{2}{*}{ Property } & Concrete mixtures & \multicolumn{2}{l}{ Number of cycles applied } & \\
& & $\mathbf{0}$ & $\mathbf{5 6}$ & $\mathbf{1 2 0}$ \\
\hline \multirow{3}{*}{ Saturation rate } & CC & 7.52 & 13.70 & 18.40 \\
$(\%)$ & CRRP 3\% & 8.20 & 11.20 & 14.50 \\
& CRRP 6\% & 9.40 & 10.50 & 13.30 \\
& CRRP 9\% & 9.80 & 10.10 & 12.60 \\
Scaling surface (g/m $\left.\mathbf{m}^{2}\right)$ & CC & 0 & 750 & 1650 \\
& CRRP 3\% & 0 & 494 & 861 \\
& CRRP 6\% & 0 & 228 & 444 \\
& CRRP 9\% & 0 & 061 & 194 \\
& CC & 50.80 & 25.56 & 15.40 \\
Compressive strength (MPa) & CRRP 3\% & 44.84 & 34.50 & 25.70 \\
& CRRP 6\% & 33.61 & 28.44 & 23.70 \\
& CRRP 9\% & 27.52 & 24.80 & 20.00 \\
\hline
\end{tabular}

\subsubsection{Visual Observation}

Figure 4 shows the visual appearance of the studied specimens (CC, CRRP 3\%, CRRP 6\%, CRRP $9 \%)$ subject to the deicing salt test. The scaling surface degree of the specimens increased with the increasing cycle number and the RRP rate. The evaluation of the specimens during the test revealed the following aspects:

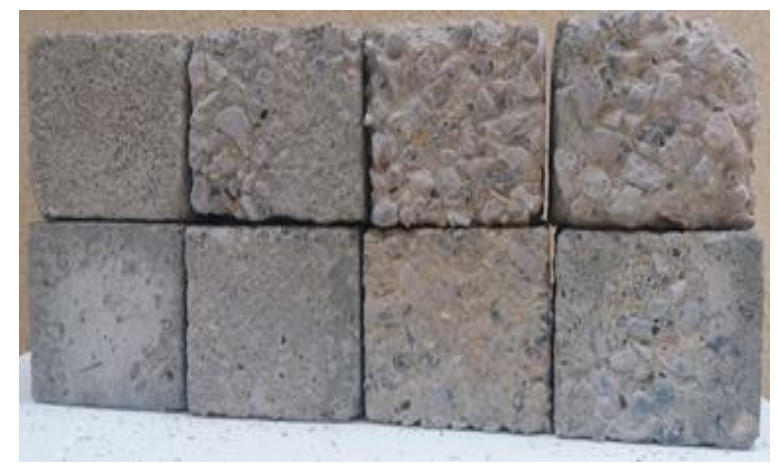

Figure 4 View of the studied specimens after the deicing salt test.

All the specimens exposed to the deicer salt test changed their colors toward brown discoloration. The trend is typically amid severe surface scaling. 
There was no evidence of surface scaling up to 15 cycles. Around the 18th cycle, the specimens showed primary flaking spots in the control concrete. Notably, the first flaking spots of rubber concrete appeared around the 41st cycle.

The 56-cycle exposure showed a moderate scaling of control specimens, consistent with the ASTMC672 criteria (some coarse aggregate visible). However, the CRRP 3\% and CRRP 6\% specimens showed slight scaling with a maximum depth of $3 \mathrm{~mm}$ (no coarse aggregate visible). Conversely, the CRRP 9\% specimens were healthy (no scaling). The present study followed the Standard ASTM C672 for comparison.

The 120 cycle exposure showed a severe scaling of control and CRRP 3\% specimens according to the ASTM C672 [11]. The coarse aggregate was visible over the whole surface (rim fractures, edges and corner fractures, and fractures with random orientation) with a damage depth from 3 to $18 \mathrm{~mm}$. However, the CRRP 6\% specimens showed a moderate scaling (some coarse aggregate visible). On the contrary, the CRRP $9 \%$ damage was weak (very slight scaling), exhibiting only a few flakes on the specimens with a depth of less than $3 \mathrm{~mm}$. The rubber concrete's high resistance to deicing salts could be due to $1.5 \%$ to $5.3 \%$ rubber air content with the RRP inclusion of $3 \%$ to $9 \%$. The absence of rubber air content in the control concrete increased the scaling-surface damage because the ice formation in the concrete network was accompanied by an increase in their volume by $9 \%$. This behavior produced the remarked cracks on the skin concrete (see Figure 5).

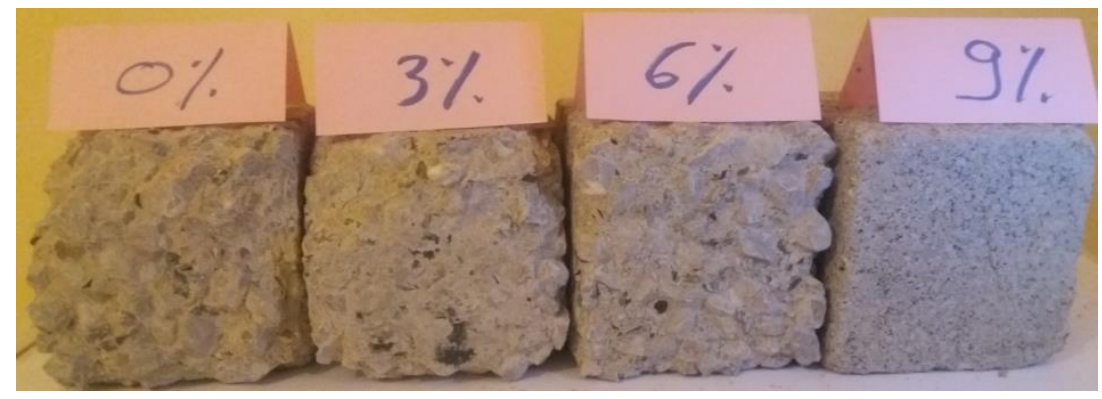

Figure 5 Cross-section of specimens exposed to deicing salt (120 cycles).

\subsubsection{Saturation Rate (Water-Uptake)}

Figure 6 shows the increase in the saturation rates of the studied concretes with the cycle number, especially for the control concrete. The observed increase was about $144 \%, 77 \%, 36 \%$, and $28 \%$ for 120 cycles, compared with the composites in the laboratory conditions, respectively. The obtained trend was due to the nature of the saline solution diluted progressively with the cyclic effect of deicing salt. Consequently, the saline solution facilitated the water penetration through the porous network of control concrete by capillary, increasing their saturation levels compared with the rubber concrete. The saturation rates of rubber concrete reduced with the bubbles-air produced by the RRP (see air content section). In the literature on the concrete subjected to deicing salt attack, this trend is frequent [20]. However, there are no studies on the durability of rubber concrete subjected to deicer salt. This result proves the very high resistance of rubber concrete to deicer salt attack, improving the durability of concrete subjected to the deicing salt solution. Thus, the excellent durability of rubber concrete to deicer salt attacks could encourage the construction industry to reuse the rubber tires as concrete aggregates. 


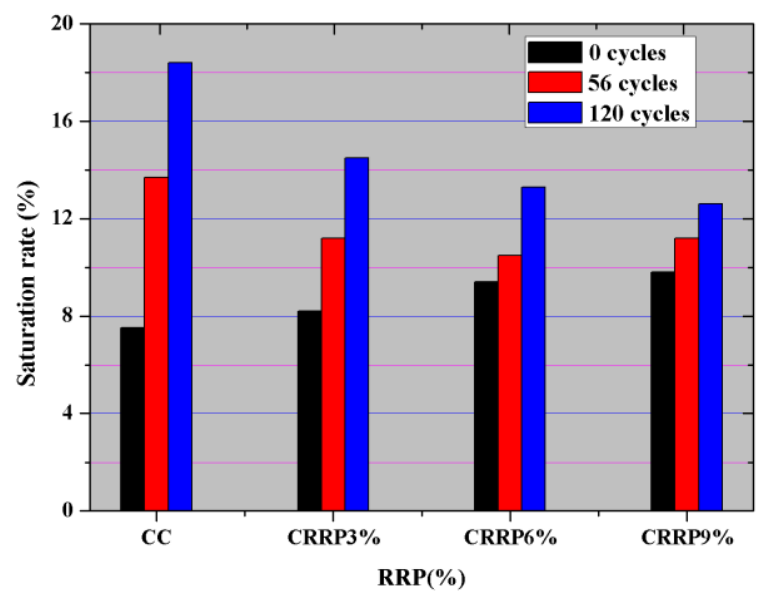

Figure 6 Influence of the RRP on the saturation rate of concrete subjected to the deicing salt test.

\subsubsection{Scaling Surface}

Figure 7 illustrates that the studied concrete, including the rubber particles (CRRP 3\%, CRRP 6\%, and CRRP 9\%), showed a high drop in their surface scaling. These declines were $48 \%, 73 \%$, and $88 \%$, respectively, compared with the control concrete for 120 cycles. The higher surface scaling resistance of rubber concrete was attributed to the air content introduced by the RRP $(1.5 \%$ to 5.3\%). Sun and Scherer [20] investigated the air content effect on the deicing salt-treated mortar durability and reported a good scaling-surface resistance. However, the literature did not report any study on the scaling-surface resistance of rubber concrete. The innovative property analyzed in the present study revealed that the RRP could significantly improve the concrete's deicer saltscaling resistance. Therefore, the RRP could be used as an air-entrainment admixture in the concrete structure to improve their durability to the deicing salt attack.

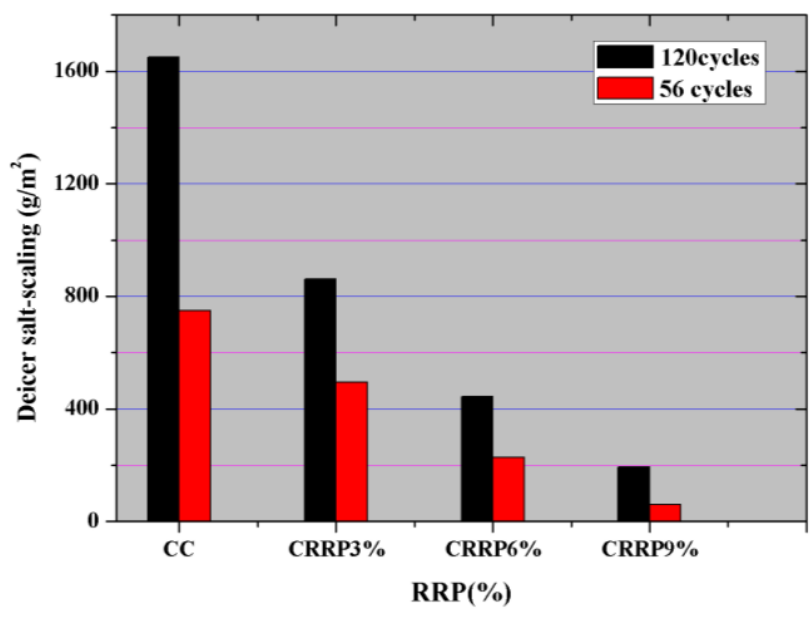

Figure 7 Effect of the RRP on the surface scaling resistance of the studied concrete subjected to the deicing salt test. 


\subsubsection{Compressive Strength}

Figure 8 represents the compressive strength of concrete, including the rubber particle content subjected to deicing salt attack. The observed results revealed that the compressive strength of studied concrete (CR, CRRP 3\%, CRRP 6\%, and CRRP 9\%) dropped sharply with rubber content and the cycle number. These drops were about $49.70 \%, 23.10 \%, 15.40 \%$, and $9.9 \%$ for the 56 exposures and $69.70 \%, 42.70 \%, 29.50 \%$, and $27.32 \%$ for the 120 exposures, compared with the reference concrete. The above behavior confirms that the rubber particles greatly reduce the concrete damage due to deicing salt $\mathrm{NaCl}$. The observed phenomenon could be explained by the fact that the rubber particles favor the entrapment of air bubbles on their rigorous faces during the mixing phase (see the air content section). Therefore, the air content alleviates the pressures due to the freeze--thaw process during the ice formation in the porous network of concrete.

Additionally, the high deformation capacity and the high compressibility of the rubber could also participate in the beneficial behavior of rubber concrete subjected to freeze-thaw cycles with the deicing salt attack. The research indicates that the air content of $5 \%$ to $6 \%$ in the concrete (by the air-entraining admixture) considerably improves concrete durability subject to freeze-thaw [15, 20]. The suggested innovative property of rubber particles could improve the durability of concrete structures exposed to deicer salt $\mathrm{NaCl}$.

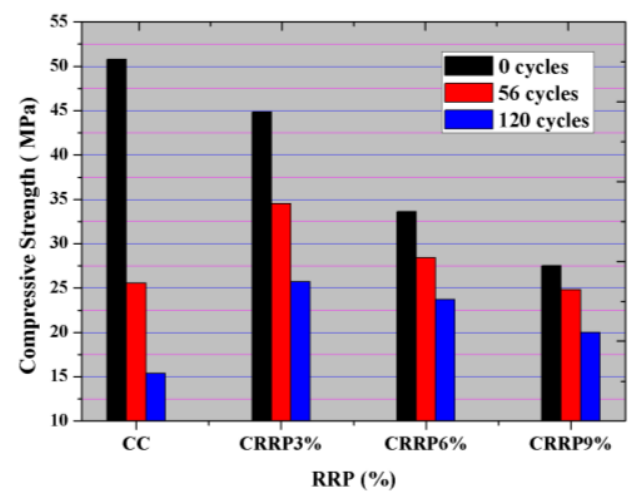

Figure 8 Effect of the RRP on compressive strength of studied concrete subjected to the deicing salt test.

\section{Conclusions}

The present study investigated the effect of reused rubber particles on the concrete durability to deicing salt $\mathrm{NaCl}$. The following conclusions were made from the study:

1) The air content results indicated that the inclusion of reused rubber particles up to $9 \%$ in the control concrete strongly increased their air content (1.5\%-5.3\%). The observed innovative property of RRP could improve the deicing salt durability of concrete.

2) Concerning the studied concretes subjected to deicing salt attack (56 and 120 cycles), the results showed a very weak scaling surface of rubber concrete than the control. The higher deicing salt-scaling resistance of rubber concrete was due to the rubber air content. The observed innovative property demonstrated that the RRP could improve the scaling surface resistance of cement-based materials to deicing salts attack. Moreover, the rubber particles could be reused 
like an air-entrainment admixture within the concrete structures to reinforce their deicing saltscaling durability.

\section{Acknowledgments}

The authors express their gratitude to the Civil Engineering Department Laboratory of Bordj Bou-Arréridj University, Civil Engineering laboratory of USTHB for his technical support during the experimental work.

\section{Author Contributions}

The authors put the research plan together. The author L. GUELMINE carried out the experimental work in the laboratory. This article has been written and corrected with the participation of all authors.

\section{Competing Interests}

The authors have declared that no competing interests exist.

\section{References}

1. Rashad AM. A comprehensive overview about recycling rubber as fine aggregate replacement in traditional cementitious materials. Int J Sustain Built Environ. 2016; 5: 46-82.

2. Alsaif A, Bernal SA, Guadagnini M, Pilakoutas K. Freeze-thaw resistance of steel fibre reinforced rubberised concrete. Constr Build Mater. 2019; 195: 450-458.

3. Pedro D, De Brito J, Veiga R. Mortars made with fine granulate from shredded tires. J Mater Civ Eng. 2013; 25: 519-529.

4. Alsaif A, Bernal SA, Guadagnini M, Pilakoutas K. Durability of steel fibre reinforced rubberised concrete exposed to chlorides. Constr Build Mater. 2018; 188: 130-142.

5. Guelmine L, Hadjab $H$, Benazzouk A. Effect of elevated temperatures on physical and mechanical properties of recycled rubber mortar. Constr Build Mater. 2016; 126: 77-85.

6. Khaloo AR, Dehestani M, Rahmatabadi P. Mechanical properties of concrete containing a high volume of tire-rubber particles. Waste Manage. 2008; 28: 2472-2482.

7. Huang X, Ranade R, Ni W, Li VC. On the use of recycled tire rubber to develop low E-modulus ECC for durable concrete repairs. Constr Build Mater. 2013; 46: 134-141.

8. Ganjian E, Khorami M, Maghsoudi AA. Scrap-tyre-rubber replacement for aggregate and filler in concrete. Constr Build Mater. 2009; 23: 1828-1836.

9. Richardson $A E$, Coventry $K A$, Ward G. Freeze/thaw protection of concrete with optimum rubber crumb content. J Clean Prod. 2012; 23: 96-103.

10. NF EN 12390-2: Essais pour béton durci - Partie 2: Confection et conservation des éprouvettes pour essais de résistance [Internet]. Boutique AFNOR; 2001. Available from: https://www.boutique.afnor.org/norme/nf-en-12390-2/essai-pour-beton-durci-partie-2confection-et-conservation-des-eprouvettes-pour-essais-deresistance/article/706427/fa043144.

11. ASTM C672/C672M - 03: Standard test method for scaling resistance of concrete surfaces exposed to deicing chemicals [Internet]. West Conshohocken, Pennsylvania: ASTM 
International; $2003 . \quad$ Available from: https://www.astm.org/DATABASE.CART/HISTORICAL/C672C672M-03.htm.

12. Fagerlund, G: "Studies of the Scaling, the Water Uptake and the Dilation of Mortar Specimens Exposed to Freezing and Thawing in NaCl Solutions", in "Freeze-Thaw and De-Icing Resistance of Concrete", RILEM Committee TC-117 FDC meeting in Lund, June, 1991, Lund Institute of Technology, Div. Building Materials, report TVBM-3048, pp 36-66.

13. Browne FP, Cady PD. Deicer scaling mechanisms in concrete. Spec Publ. 1975; 47: 101-120.

14. Litvan GG. Frost action in cement in the presence of de-icers. CemConcr Res. 1976; 6: 351-356.

15. Valenza JJ, Scherer GW. Mechanism for salt scaling of a cementitious surface. Mater Struct. 2007; 40: 259-268.

16. Marchand J. The deicer salt scaling deterioration of concrete-an overview. ACl Spec Publ. 1994; 145: 1-46.

17. ASTM C231-03: Standard Test Method for Air Content of Freshly Mixed Concrete by the Pressure Method [Internet]. West Conshohocken, Pennsylvania: ASTM International; 2003. Available from: http://www.astm.org/cgi-bin/resolver.cgi?C231-03.

18. Kardos AJ, Durham SA. Strength, durability, and environmental properties of concrete utilizing recycled tire particles for pavement applications. Constr Build Mater. 2015; 98: 832-845.

19. Siddique R, Naik TR. Properties of concrete containing scrap tire rubber-An overview. Waste Manage. 2004, 24: 563-569.

20. Sun Z, Scherer GW. Effect of air voids on salt scaling and internal freezing. CemConcr Res. 2010; 40: 260-270.

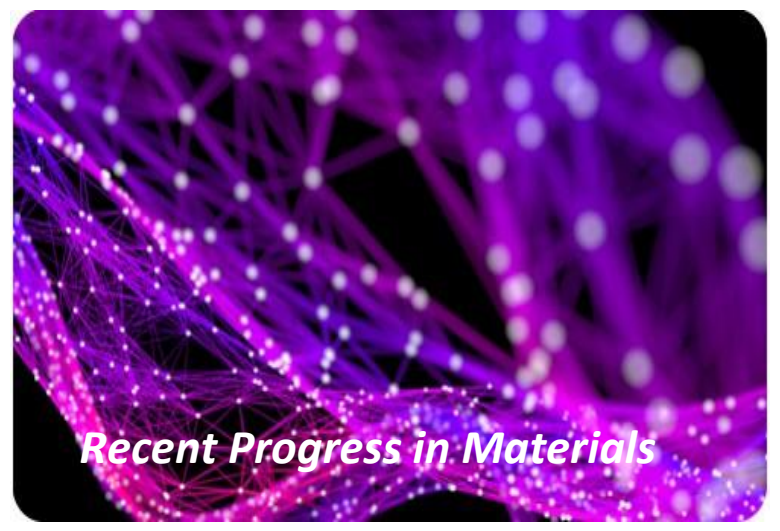

Enjoy Recent Progress in Materials by:

1. Submitting a manuscript

2. Joining in volunteer reviewer bank

3. Joining Editorial Board

4. Guest editing a special issue

For more details, please visit:

http://www.lidsen.com/journals/rpm 